\title{
DMS atmospheric concentrations and sulphate aerosol indirect radiative forcing: a sensitivity study to the DMS source representation and oxidation
}

\author{
O. Boucher ${ }^{1}$, C. Moulin ${ }^{2}$, S. Belviso ${ }^{2}$, O. Aumont ${ }^{3}$, L. Bopp ${ }^{2}$, E. Cosme ${ }^{4}$, R. von Kuhlmann ${ }^{5}$, M. G. Lawrence ${ }^{5}$, \\ M. Pham ${ }^{6}$, M.S. Reddy ${ }^{1}$, J. Sciare ${ }^{2}$, and C. Venkataraman ${ }^{7}$ \\ ${ }^{1}$ Laboratoire d'Optique Atmosphérique, CNRS UMR 8518, USTL, Villeneuve d'Ascq, France \\ ${ }^{2}$ Laboratoire des Sciences du Climat et de l'Environnement, CEA/CNRS, Gif sur Yvette, France \\ ${ }^{3}$ Laboratoire d'Océanographie Dynamique et de Climatologie, CNRS/UPMC/IRD, Paris, France \\ ${ }^{4}$ Laboratoire de Glaciologie et Géophysique de l'Environnement, CNRS, Saint-Martin-d'Hères, France \\ ${ }^{5}$ Max Planck Institute for Chemistry, Air Chemistry Department, Mainz, Germany \\ ${ }^{6}$ Service d'Aéronomie, CNRS/UPMC/UVSQ, Paris, France \\ ${ }^{7}$ Centre for Environmental Science and Engineering, Indian Institute of Technology, Bombay, India
}

Received: 28 June 2002 - Published in Atmos. Chem. Phys. Discuss.: 30 August 2002

Revised: 2 December 2002 - Accepted: 12 December 2002 - Published: 28 January 2003

\begin{abstract}
The global sulphur cycle has been simulated using a general circulation model with a focus on the source and oxidation of atmospheric dimethylsulphide (DMS). The sensitivity of atmospheric DMS to the oceanic DMS climatology, the parameterisation of the sea-air transfer and to the oxidant fields have been studied. The importance of additional oxidation pathways (by $\mathrm{O}_{3}$ in the gas- and aqueous-phases and by $\mathrm{BrO}$ in the gas phase) not incorporated in global models has also been evaluated. While three different climatologies of the oceanic DMS concentration produce rather similar global DMS fluxes to the atmosphere at $24-27 \mathrm{Tg} \mathrm{S} \mathrm{yr}^{-1}$, there are large differences in the spatial and seasonal distribution. The relative contributions of $\mathrm{OH}$ and $\mathrm{NO}_{3}$ radicals to DMS oxidation depends critically on which oxidant fields are prescribed in the model. Oxidation by $\mathrm{O}_{3}$ appears to be significant at high latitudes in both hemispheres. Oxidation by $\mathrm{BrO}$ could be significant even for $\mathrm{BrO}$ concentrations at sub-pptv levels in the marine boundary layer. The impact of such refinements on the DMS chemistry onto the indirect radiative forcing by anthropogenic sulphate aerosols is also discussed.
\end{abstract}

Correspondence to: O. Boucher

(boucher@loaser.univ-lille1.fr)

\section{Introduction}

Although a lot is now understood about the global sulphur cycle, some uncertainties remain, in particular about the emission strength of dimethylsulphide (DMS). The DMScloud albedo-climate feedback loop proposed by Shaw (1983) and Charlson et al. (1987) generated many studies, but it is still not clear whether this feedback mechanism involving the biosphere, the ocean, and the atmosphere has played an important role in past climates, and whether it can play a role in future climate change (Bopp et al., 2002a, 2002b). Several modelling studies attempted to model the global distribution of DMS (e.g. Chin et al., 1998; Sciare et al., 2000b).

Recently Jones et al. (2001) showed in a global model study that using the parameterisation of DMS sea-air exchange of Wanninkhof (1992) instead of Liss and Merlivat (1986) results into a doubling of the DMS emission flux and a $25 \%$ reduction in the indirect radiative forcing due to anthropogenic sulphate aerosols. This is because the increase in the DMS flux causes an increase in the concentration of sulphate aerosol, thus reducing the cloud susceptibility to anthropogenic aerosols. Nightingale et al. (2000) found that observations of the sea-air exchange rate scatter between the two above-mentioned parameterisations and suggested a revised parameterisation which will be used in the present study. 
The estimation of the yield of $\mathrm{SO}_{2}$ from DMS oxidation is one of the critical points required to evaluate the relative contribution of DMS in the marine sulphate aerosols. Whereas the $\mathrm{OH}$ radical is clearly identified as a major DMS oxidant in the atmosphere, strong uncertainties still remain in the estimation of $\mathrm{SO}_{2}$ yields from the $\mathrm{DMS}+\mathrm{OH}$ reaction. Another uncertainty in the $\mathrm{SO}_{2}$ yield from the DMS oxidation concerns the role played by other radicals than $\mathrm{OH}$, and especially nitrate $\left(\mathrm{NO}_{3}\right)$ and bromide oxide $(\mathrm{BrO})$ radicals for the most important. Contrary to the reaction $\mathrm{DMS}+\mathrm{OH}$ which proceeds by two different pathways (the $\mathrm{H}$-abstraction channel leading to $\mathrm{SO}_{2}$ and the $\mathrm{OH}$-addition channel leading to dimethylsulphoxide (DMSO)), DMS oxidising mechanisms with $\mathrm{NO}_{3}$ and $\mathrm{BrO}$ only proceed through the addition channel leading to DMSO for $\mathrm{BrO}$ radicals and the $\mathrm{H}$-abstraction channel leading to $\mathrm{SO}_{2}$ for $\mathrm{NO}_{3}$ radicals. Unlike the DMS oxidation by $\mathrm{OH}$, there is no uncertainty in the $\mathrm{SO}_{2}$ yield from the DMS oxidation by $\mathrm{NO}_{3}$ and $\mathrm{BrO}$ radicals. However, the role of these radicals on the fate of DMS remains elusive since no field experiments were carried out with simultaneous measurements of atmospheric DMS, and $\mathrm{BrO}$ and $\mathrm{NO}_{3}$ radicals. The atmospheric fate of DMSO is also uncertain. If DMSO is preferentially oxidised to methanesulfonic acid (MSA), the production of $\mathrm{SO}_{2}$ and sulphate aerosols in the clean MBL will be less than presently thought.

The aqueous-phase reaction of DMS and $\mathrm{O}_{3}$ expected to occur in cloud droplets, has been indicated to be of atmospheric importance (Lee and Zhou, 1994; Gershenzon et al., 2001). This reaction, as well as that in the gas phase, is usually not considered in global models of the sulphur cycle. Campolongo et al. (1999) stressed the importance of multiphase chemistry for determining accurately the latitudinal dependence of the MSA to nss- $\mathrm{SO}_{4}^{2-}$ ratio but did not estimate its importance for DMS oxidation itself. As mentioned above, there are also several indications that reaction with $\mathrm{BrO}$ can be a significant loss of DMS in the marine boundary layer (MBL) during daytime. This was first suggested by Toumi (1994) based on box model calculations. Sciare et al. (2000a) found from simultaneous measurements of seawater and atmospheric DMS, OH radicals, and the boundary layer height that the diurnal variation of gas-phase DMS in the Tropical Atlantic Ocean could not be explained by the oxidation with $\mathrm{OH}$ alone. They state that 3 pptv of $\mathrm{BrO}$ prescribed during daytime could resolve the discrepancy. Similar problems with too strong measured diurnal variation of DMS compared to model calculations with standard chemistry were also found by Yvon et al. (1996). Box model calculations based on recent kinetic data emphasize the possible strong effects of $\mathrm{BrO}$ on DMS and DMSO concentrations (Ingham et al., 1999). Recently, von Glasow et al. (2002) calculated with a 1D model that consideration of $\mathrm{BrO}$ increases the DMS oxidation rate by $63 \%$ for remote MBL conditions. However, a large uncertainty is associated with the amount and speciation of inorganic bromine, $\mathrm{Br}_{x}$, in the MBL.

In this paper we use three different distributions of the oceanic DMS concentrations, two parameterisations of the sea-air transfer function, and two distributions of atmospheric oxidants to predict the atmospheric fate of DMS and its impact on the sulphur cycle. We also test the importance of the three additional above-mentioned DMS oxidation pathways.

\section{Description of the models and experiments}

\subsection{Sulphur cycle model}

We use here a model of the global sulphur cycle developed in the framework of the general circulation model of the Laboratoire de Météorologie Dynamique, LMD-ZT. This model is fully described and evaluated in Boucher et al. (2002). It has been used in Boucher and Pham (2002) to predict the evolution of the sulphur cycle from 1850 to 1998 and by Cosme et al. (2002) to study the sulphur cycle in the high southern latitudes. Only aspects relevant to DMS sources and sinks and $\mathrm{SO}_{2}$ oxidation are repeated here.

DMS is emitted using the sea to air parameterisation of Liss and Merlivat (1986) or Nightingale et al. (2000). It is oxidised in the gas phase by $\mathrm{OH}$ and $\mathrm{NO}_{3}$ radicals. While the oxidation of DMS by $\mathrm{NO}_{3}$ only produces $\mathrm{SO}_{2}$, the oxidation by $\mathrm{OH}$ produces both $\mathrm{SO}_{2}$ and DMSO through the addition channel and only $\mathrm{SO}_{2}$ through the abstraction channel. DMSO is oxidised in the gas-phase by $\mathrm{OH}$ to produce $\mathrm{SO}_{2}(60 \%)$ and MSA (40\%) and is also subject to in-cloud and below-cloud scavenging (Boucher et al., 2002). No heterogeneous sink for DMS and DMSO is included. Sulphur dioxide, $\mathrm{SO}_{2}$, is oxidised in the gas phase by $\mathrm{OH}$ and in the aqueous phase by $\mathrm{O}_{3}$ and $\mathrm{H}_{2} \mathrm{O}_{2}$. All reaction rates are given in Boucher et al. (2002).

The monthly concentrations of all oxidants except $\mathrm{H}_{2} \mathrm{O}_{2}$ are prescribed from the IMAGES (Pham et al., 1995) or the MATCH-MPIC (von Kuhlmann, 2001; von Kuhlman et al., 2003) chemical transport models. The diurnal variations of the oxidant fields are taken from the IMAGES model only and are applied in LMD-ZT with a timestep of 30 minutes. Hydrogen peroxide, $\mathrm{H}_{2} \mathrm{O}_{2}$, is predicted interactively in the model from prescribed $\mathrm{HO}_{2}$ concentrations and $\mathrm{H}_{2} \mathrm{O}_{2}$ photodissociation rates. It also undergoes dry and wet scavenging and is depleted upon $\mathrm{SO}_{2}$ oxidation, as described in Boucher et al. (2002).

\subsection{Experiment design}

Our model runs are for 18 months and we present results for the last 12 months. All runs are for the same meteorology so the differences in the runs are only due to differences in the DMS emission or oxidation. The indirect radiative forcing due to sulphate aerosols is estimated as the difference in top-of-atmosphere radiative fluxes obtained in two simulations with and without the anthropogenic emissions of sulphur species, but with the same oxidant fields (except $\mathrm{H}_{2} \mathrm{O}_{2}$ ). 
Table 1. Characteristics of the experiments performed in this study

\begin{tabular}{clllc}
\hline Experiment & Sea-air transfer function & Oxidant fields & Oceanic DMS climatology & Additional DMS oxidation \\
\hline EXP1 & Nightingale et al. (2000) & IMAGES model & Kettle and Andreae (2000) & No \\
EXP2 & Nightingale et al. (2000) & IMAGES model & Belviso et al. (2002) & No \\
EXP3 & Nightingale et al. (2000) & IMAGES model & Aumont et al. (2002) & No \\
EXP4 & Liss and Merlivat (1986) & IMAGES model & Kettle and Andreae (2000) & No \\
EXP5 & Nightingale et al. (2000) & MATCH model & Kettle and Andreae (2000) & No \\
EXP6 & Nightingale et al. (2000) & IMAGES model & Kettle and Andreae (2000) & DMS+O 3 gas/aqueous \\
EXP7 & Nightindale et al. (2000) & IMAGES model & Kettle and Andreae (2000) & DMS + BrO \\
\hline
\end{tabular}

We follow Boucher and Lohmann (1995) and Boucher and Pham (2002) to estimate the cloud properties from the sulphate mass concentration. This calculation is only diagnostic and therefore only includes the first indirect effect (change in cloud optical properties for a fixed liquid water content). Our estimate is for sulphate aerosols only, but to some extent sulphate aerosols can be used as a proxy for the total anthropogenic aerosol. While improvements on the parameterisation of the aerosol indirect effects are desirable (Lohmann et al., 2000), our parameterisation is still useful to perform the sensitivity experiments of the present study.

Table 1 gives the list and characteristics of the seven experiments performed in this study. EXP1 is our baseline experiment. The sensitivity to the oceanic DMS distribution is evaluated from simulations EXP1, EXP2, and EXP3. The role of the sea-air transfer function is examined by comparing EXP1 and EXP4. EXP1 and EXP5 can be used to estimate the sensitivity of the results to the prescribed oxidant distributions. Finally, the importance of three more pathways for DMS oxidation, not yet incorporated in global models, is investigated in the simulations EXP6 and EXP7.

\subsection{Oceanic DMS datasets}

We test here three different distributions of the oceanic DMS. The first one is the updated climatology of Kettle and Andreae (2000) which is derived from a compilation of measurements of DMS in the sea water and an interpolation procedure in regions where no data are available (Kettle et al., 1999). In this sense the seasonal variability of DMS in the mid and high latitudes of the Southern Hemisphere is better constrained in the spring and summer seasons than in autumn and winter (Curran and Jones, 2000). This climatology is widely used in global models of the sulphur cycle (e.g. Jones et al., 2001; Boucher and Pham, 2002). It is used here in the baseline experiment (EXP1) as well as in EXP4, EXP5, EXP6, and EXP7. The work of Belviso et al. (2002) forms the basis for our second dataset and is used in EXP2. The global distribution of oceanic DMS concentration is estimated from the 1998-2001 SeaWiFS (satellitebased) measurements of the sea-surface chlorophyll $a$ (Chl a) content and from a phytoplanktonic community structure index which are then empirically linked to the DMS concentration. In EXP2, the phytoplanktonic community structure index is a non-linear function of $\mathrm{Chl} a$, so that sea surface DMS concentration was computed solely from the SeaWiFS ocean color measurements. The oceanic DMS concentration is prescribed globally as monthly means based on a four-year climatology with the reservations that (1) a minimum value of $0.2 \mathrm{nmol} \mathrm{l}^{-1}$ is assumed in regions where no SeaWiFS data are available in particular at high latitudes in wintertime due to the low insolation and in areas covered of ice, and (2) a maximum value of $50 \mathrm{nmol}^{-1}$ is also introduced to overcome the few unrealistic values obtained at very large Chl $a$ content in coastal waters. Our third DMS climatology, used in EXP3, originates in the modelling work of Aumont et al. (2002). In this study the DMS concentration in sea water is derived from the concentration of Chl $a$ and the phytoplanktonic community structure index which are both independently calculated by a global 3-D ocean carbon cycle model. Moreover, the diagnostics of DMS concentrations used by Belviso et al. (2002) and by Aumont et al. (2002) are slightly different.

\subsection{Oxidant fields}

Oxidant fields from the IMAGES model are used in all experiments except EXP5 in which we use instead the oxidant fields from MATCH-MPIC. The major features of IMAGES are described in Müller and Brasseur (1995) and references herein. The IMAGES model calculates the distribution of about 60 species, including $\mathrm{O}_{3}, \mathrm{HO}_{x}, \mathrm{NO}_{x}$, sulfur oxides, acetone, methane, non-methane hydrocarbons (NMHC: ethane, ethylene, propylene, isoprene, $\alpha$-pinene, propane, and $n$-butane as a surrogate for the other higher hydrocarbons) and their degradation products. Heterogeneous reactions of $\mathrm{NO}_{3}$ and $\mathrm{N}_{2} \mathrm{O}_{5}$ on prognostic sulfate distributions are taken into account. The model uses emissions described in Müller and Brasseur (1995) except for fossil fuel emissions of $\mathrm{SO}_{x}$ and $\mathrm{NO}_{x}$, as well as biogenic continental emissions of $\mathrm{NMHC}$ and $\mathrm{NO}_{x}$, where GEIA inventories have been used, and for biomass burning (Granier et al., 1996) 
(a)
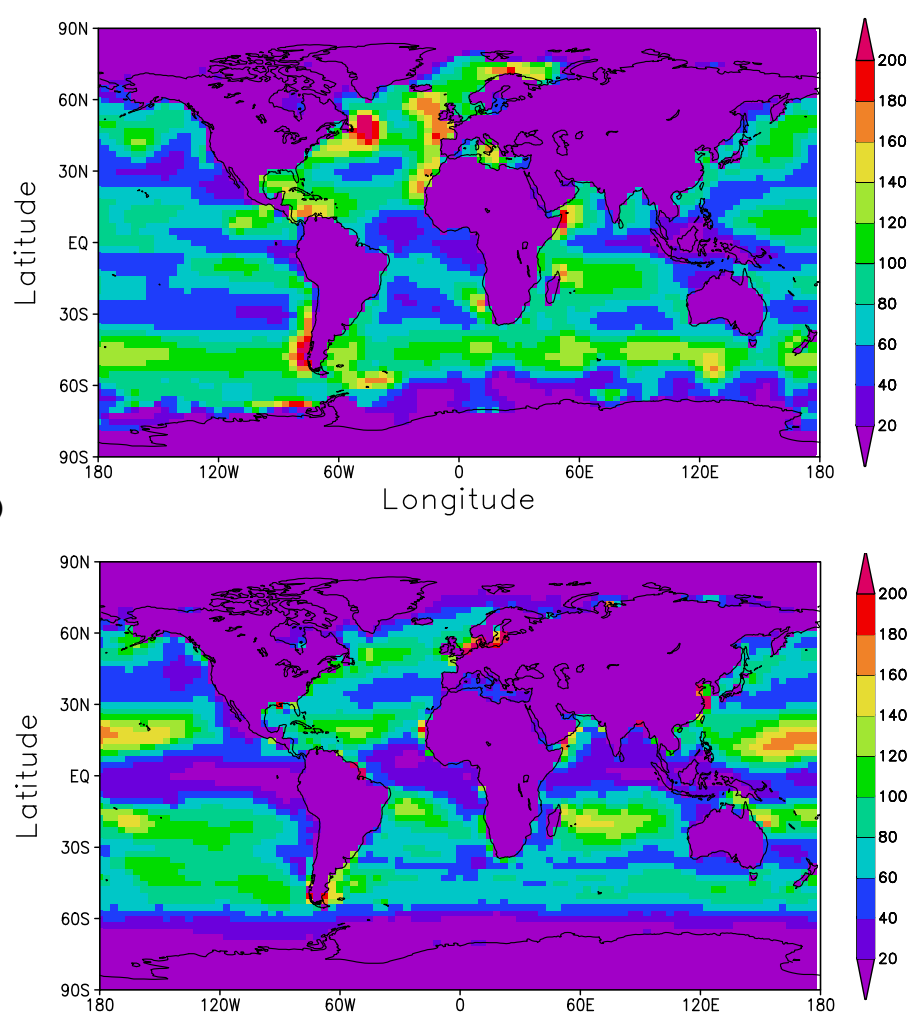

(b)

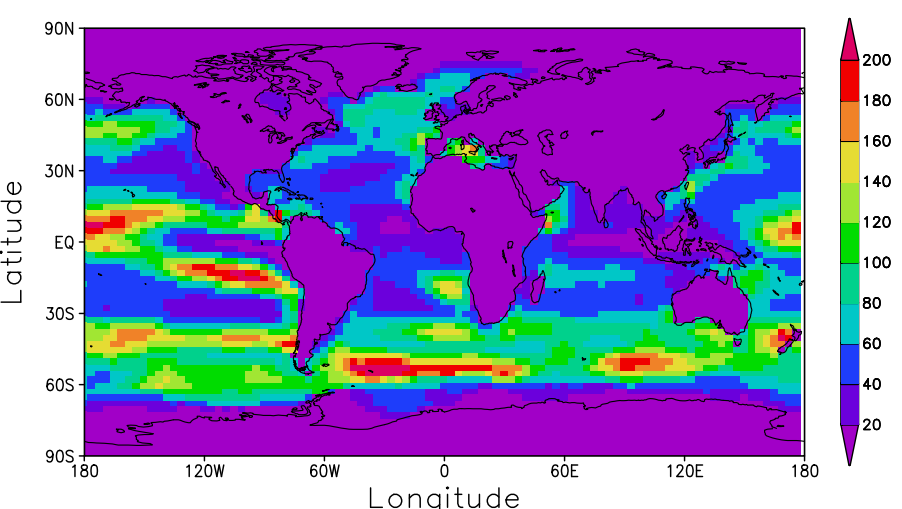

(c)

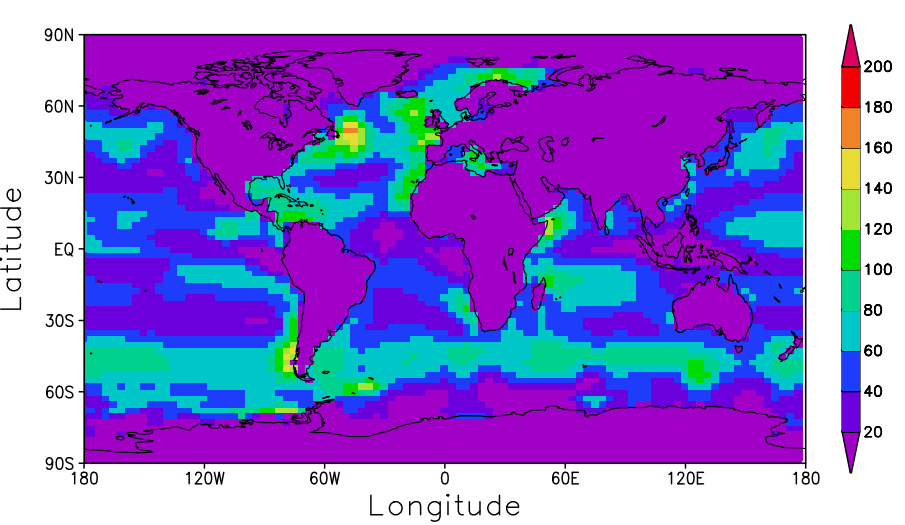

Fig. 1. Spatial distribution of the annually-averaged oceanic DMS flux (mg S m${ }^{-2} \mathrm{yr}^{-1}$ ) from (a) EXP1, (b) EXP2, (c) EXP3, and (d) EXP4. 


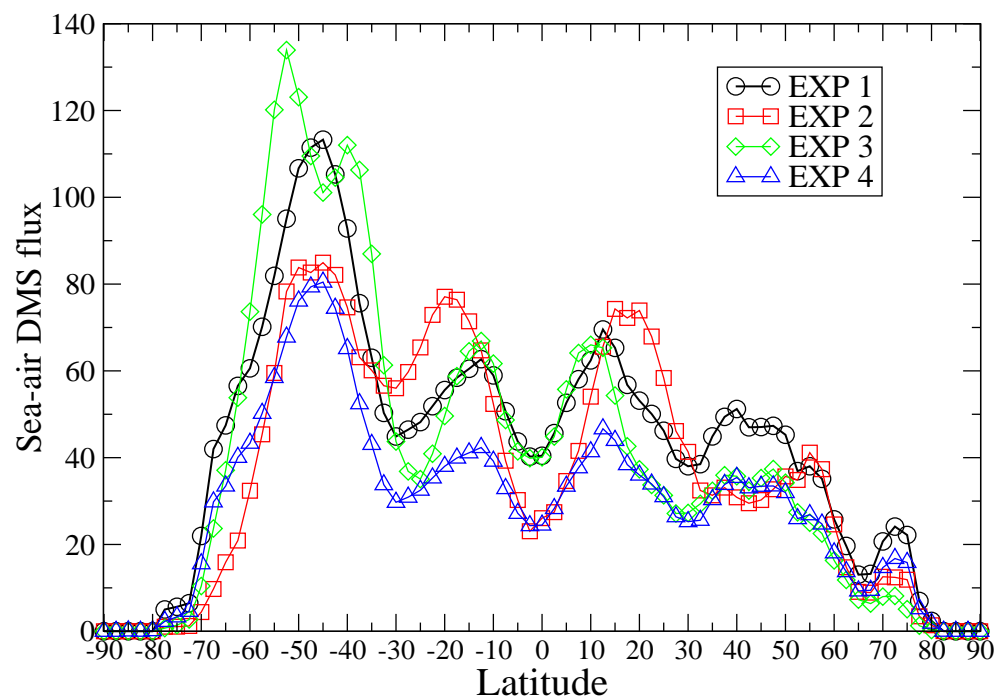

Fig. 2. Zonally- and annually-averaged oceanic DMS flux ( $\left.\mathrm{mg} \mathrm{S} \mathrm{m}^{-2} \mathrm{yr}^{-1}\right)$.

and lightning (Pickering et al., 1998; Price et al., 1997). In this version, no emissions from ocean-going ships have been included.

The model MATCH-MPIC includes up to C5-hydrocarbon chemistry (ethane, propane, ethene, propene, isoprene, higher alkane surrogate) and uses up-to-date emissions mostly from EDGAR or GEIA inventories. Emissions from ocean-going ships represent an additional source of $2.6 \mathrm{Tg} \mathrm{N} \mathrm{yr}^{-1}$ and follow the distribution of Corbett et al. (1999). Heterogeneous reaction of $\mathrm{N}_{2} \mathrm{O}_{5}$ on sulphate aerosols is included based on monthly mean fields from Dentener and Crutzen (1993). Further details are described in von Kuhlmann et al. (2003), von Kuhlmann (2001) and Lawrence et al. (1999).

\subsection{Additional oxidation pathways}

In EXP6, we further consider oxidation of atmospheric DMS by ozone in gas and aqueous phase. While the photochemical sources and sinks of $\mathrm{OH}$ and $\mathrm{NO}_{3}$ radicals are such that the $\mathrm{OH}$ reaction occurs during daytime and the $\mathrm{NO}_{3}$ reaction at night, the aqueous phase ozone reaction would occur during both periods. The reaction was recently investigated as a function of temperature (274-300 K), over a significant range of gas densities from about $10^{15}$ to $10^{16} \mathrm{~cm}^{-3}$ (Gershenzon et al., 2001). The temperaturedependent, second-order aqueous reaction constant was estimated as $5.310^{12} \exp (-2600 / T) \mathrm{M}^{-1} \mathrm{~s}^{-1}$, and was about six orders of magnitude larger than the corresponding gasphase rate constant. For this latter rate constant we use the upper limit given by Martinez and Herron (1978) of $510^{2} \mathrm{M}^{-1} \mathrm{~s}^{-1}$ (or $8.310^{-19} \mathrm{~cm}^{3} \mathrm{molec}^{-1} \mathrm{~s}^{-1}$ ). The concentrations of DMS and $\mathrm{O}_{3}$ in the cloud phase are computed assuming Henry's law equilibrium. Note finally that the gas-phase reaction with $\mathrm{O}_{3}$ produces $\mathrm{SO}_{2}$ only, while the aqueous-phase reaction with $\mathrm{O}_{3}$ produces DMSO only.

In order to get an indication of the importance of the oxidation of DMS by $\mathrm{BrO}$ a simple sensitivity simulation is performed. In the EXP7 experiment we specify a constant mixing ratio for $\mathrm{BrO}$ of $1 \mathrm{pptv}$ during daytime in the first four model layers (i.e. up to an altitude of approximately $1.3 \mathrm{~km})$ and zero elsewhere and at night. This value is essentially below the detection limit of current measurement techniques, and has been found to be exceeded in some instances (e.g. Hausmann and Platt, 1994; Hebestreit et al., 1999). Typical mixing ratios of a few pptv have been calculated in other modeling studies (Toumi, 1994; Ingham et al., 1999; von Glasow et al., 2002) and were also supported in the study of Sciare et al. (2000a). The rate constant of $1.310^{-14} \exp (1033 / T) \mathrm{cm}^{3}$ molec $^{-1} \mathrm{~s}^{-1}$ used here has been determined by Nakano et al. (2001) and is in agreement with the value obtained by Ingham et al. (1999) at $298 \mathrm{~K}$. The temperature dependence is somewhat stronger than the recommendation in DeMore et al. (1997). The oxidation of DMS by $\mathrm{BrO}$ produces only DMSO (Ingham et al., 1999).

\section{Results and discussion}

\subsection{DMS flux to the atmosphere}

Using the sea-air parameterisation of Nightingale et al. (2000) and the wind fields of the LMD-ZT model the three DMS datasets considered here produce global DMS fluxes of 24-27 Tg S $\mathrm{yr}^{-1}$. Our total emission rates for DMS are significantly larger than those of Koch et al. (1999), Barth et al. (2000), and Chin et al. (2000), which are 10.7, 15.5, and 13.3 $\mathrm{Tg} \mathrm{S} \mathrm{yr}^{-1}$, respectively, and were obtained using different methodologies or DMS concentration fields. Although 

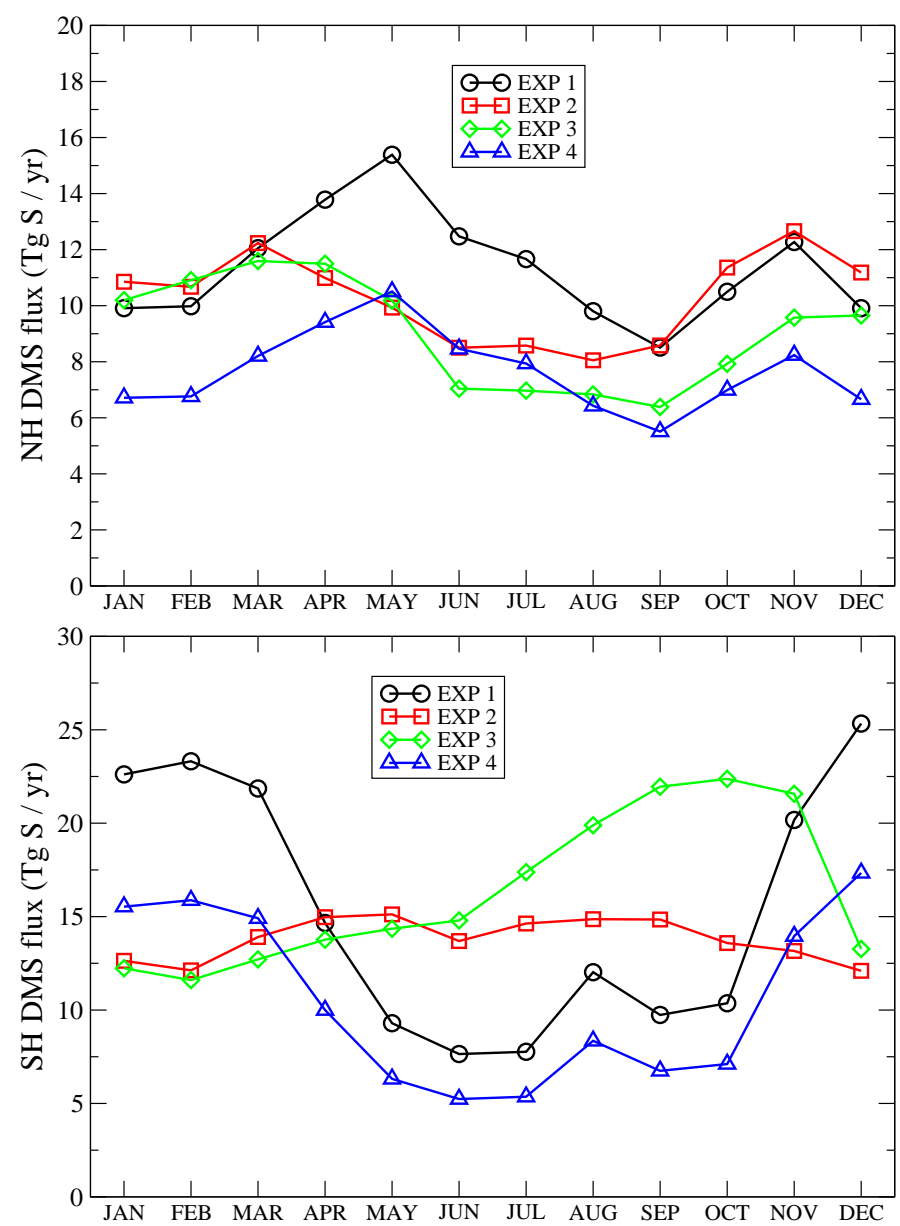

Fig. 3. Seasonal variation of the oceanic DMS flux $\left(\mathrm{Tg} \mathrm{S} \mathrm{yr}^{-1}\right)$ averaged over the Northern Hemisphere (top) and the Southern Hemisphere (bottom).

significantly larger due to the choice of the Nightingale et al. (2000) parameterization, our emission rates are within the range of 10 to $40 \mathrm{Tg} \mathrm{S} \mathrm{yr}^{-1}$ usually accepted for DMS emissions (Penner et al., 2001).

There are however significant disagreements in the spatial (Figs. 1 and 2) and seasonal (Fig. 3) distributions of the DMS flux. There are patches of large DMS flux in the North Atlantic ocean in the EXP1 simulation (Kettle and Andreae, 2000) which do not exist in EXP2 and EXP3. One can also note that the Aumont et al. climatology (EXP3) produces a more inhomogeneous DMS flux. However, the zonal averages of the DMS flux exhibit similar behaviours in the first three experiments, with minima and maxima positioned at about the same latitudes (Fig. 2). Figure 3 shows the seasonal variations of the hemispherically-averaged DMS fluxes. The differences are particularly large in the Southern Hemisphere. The DMS flux from the Kettle and Andreae database (EXP1) exhibits a large seasonal cycle with low emissions during May to July, whereas the DMS flux predicted using the SeaWiFS data (EXP2) has a rather flat seasonal variation. The DMS flux from Aumont et al. (EXP3) exhibits a maximum in September-October when Kettle and Andreae (2000) predict a secondary minimum. In the Northern Hemisphere, the three climatologies produce more consistent DMS fluxes.

Using the less sophisticated parameterisation of Liss and Merlivat (1986) instead of Nightingale et al. (2000) decreases the global DMS flux from 26.8 to $18.2 \mathrm{TgS} \mathrm{yr}^{-1}$ for the Kettle and Andreae (2000) climatology. The reduction in flux is uniformly distributed throughout the year (Fig. 3). These results are quantitatively consistent with those of Jones et al. (2001).

\subsection{Atmospheric DMS concentrations}

Figure 4 shows the spatial distribution of DMS mixing ratio at the surface in the EXP1, EXP2, EXP3, and EXP4 experiments. Once again significant differences can be observed. In contrast to EXP2, EXP1 shows among the largest annually-averaged DMS mixing ratios south of $60^{\circ} \mathrm{S}$ and more specifically in the Pacific sector of the seasonal ice zone (Bellingshausen Sea) where the phytoplanktonic biomass 
(a)
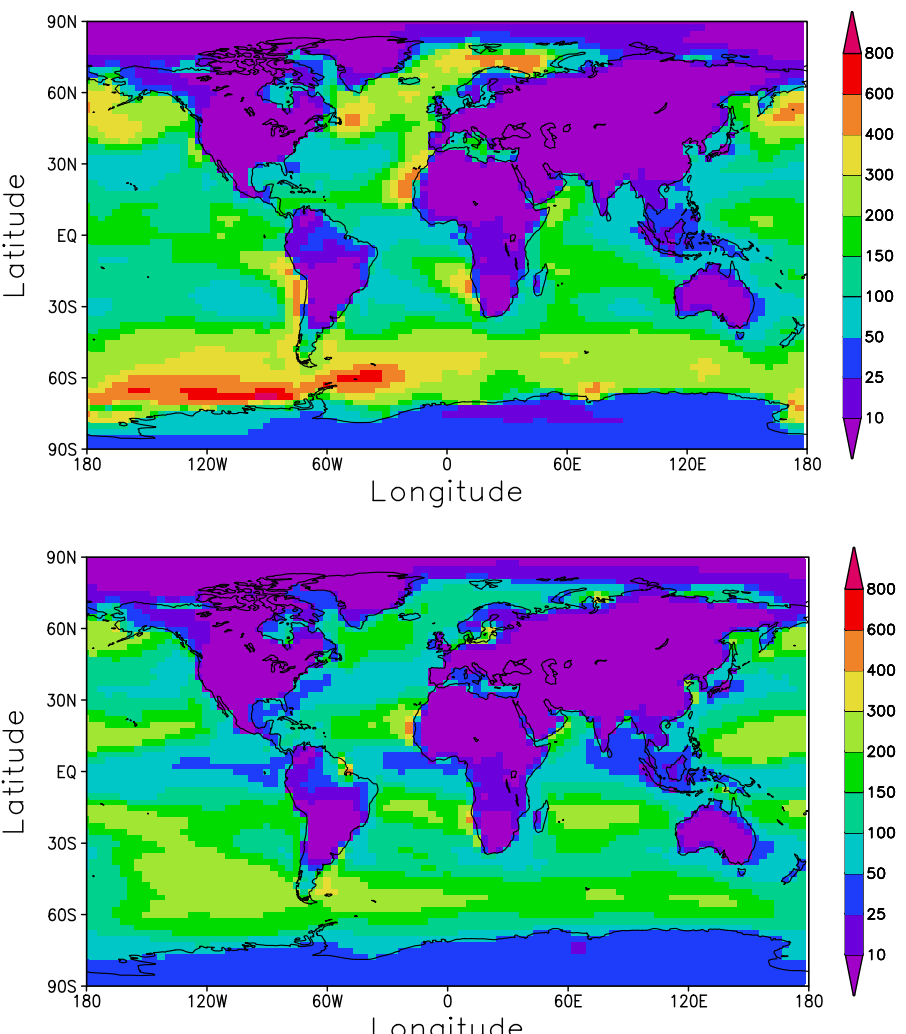

(b)

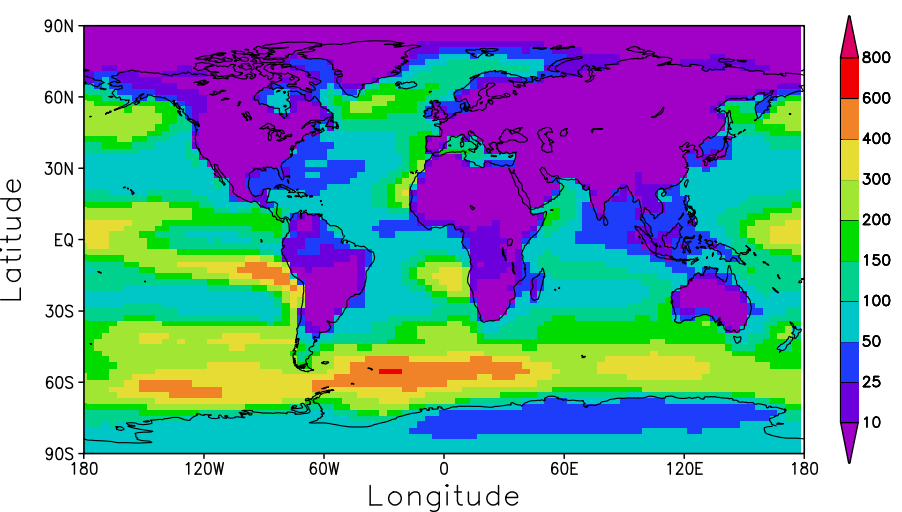

(c)

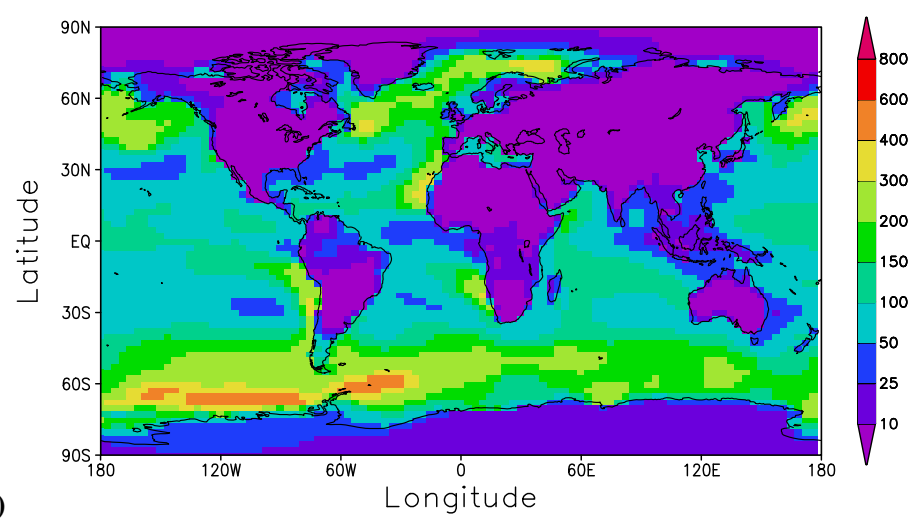

(d)

Fig. 4. Annually-averaged atmospheric DMS mixing ratio (pptv) at the surface from (a) EXP1, (b) EXP2, (c) EXP3, and (d) EXP4. 
a)
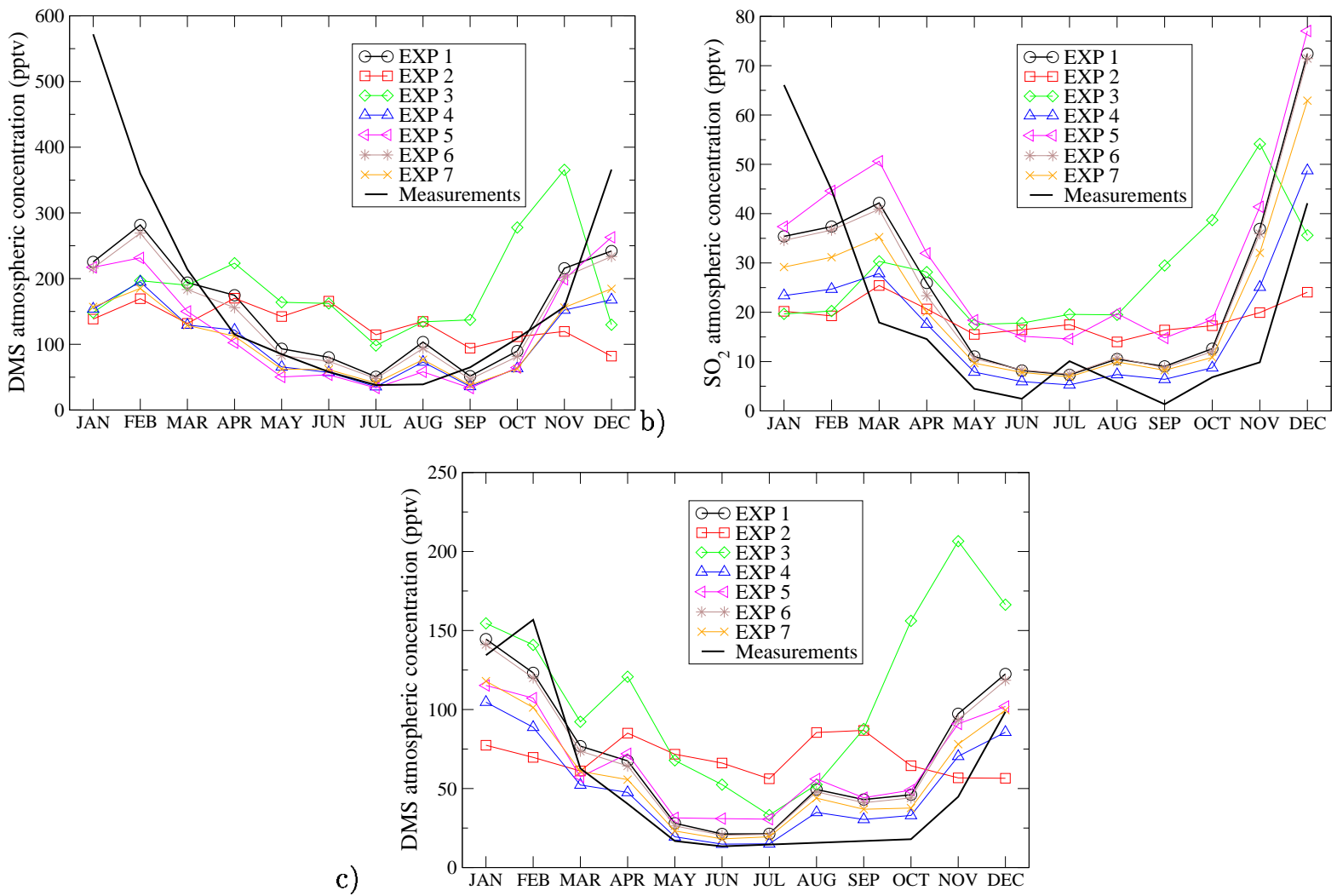

Fig. 5. Comparison of simulated and measured monthly-mean atmospheric mixing ratios (pptv): (a) DMS at Amsterdam Island ( $37.83^{\circ} \mathrm{S}$ $77.50^{\circ} \mathrm{E}$; data from Sciare et al., 2000b), (b) $\mathrm{SO}_{2}$ at Amsterdam Island (data from Putaud et al., 1992), and (c) DMS at Cape Grim (40.68 ${ }^{\circ} \mathrm{S}$ $144.68^{\circ} \mathrm{E}$; data from Ayers et al., 1991).

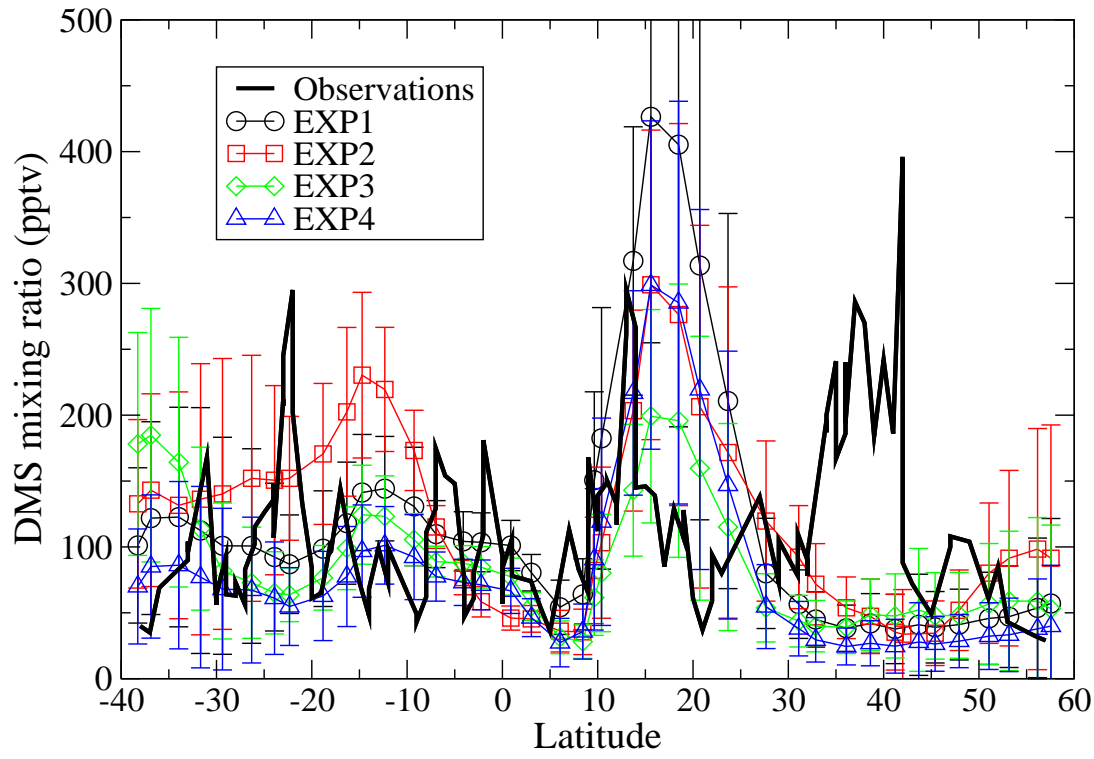

Fig. 6. Comparison of simulated and measured atmospheric mixing ratios of DMS (pptv) during the Albatross cruise. The model values are averages for the one-month period corresponding to the cruise, with standard deviations of daily means around monthly means. Observations are from Sciare et al. (2000a). 
Table 2. Characteristics of the global DMS budget and sulphate aerosol indirect radiative forcing (RF) in the seven experiments. Emission

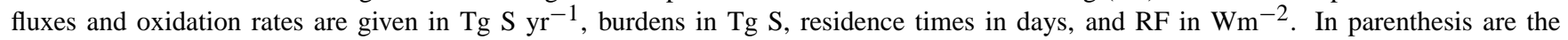
percentage contributions to the sources and sinks of DMS.

\begin{tabular}{|c|c|c|c|c|c|c|c|}
\hline & EXP1 & EXP2 & EXP3 & EXP4 & EXP5 & EXP6 & EXP7 \\
\hline $\begin{array}{l}\text { Oceanic DMS } \\
\text { emission flux }\end{array}$ & $26.8 *(99 \%)$ & $24.1(99 \%)$ & $25.4(99 \%)$ & $18.2(98 \%)$ & $26.8(99 \%)$ & $26.8(99 \%)$ & $26.8(99 \%)$ \\
\hline $\begin{array}{l}\text { Oceanic DMS } \\
\text { emission flux }(\mathrm{NH})\end{array}$ & $11.4 *(42 \%)$ & $10.3(42 \%)$ & $9.1(35 \%)$ & $7.6(41 \%)$ & $11.4(42 \%)$ & $11.4(42 \%)$ & $11.4(42 \%)$ \\
\hline $\begin{array}{l}\text { Oceanic DMS } \\
\text { emission flux (SH) }\end{array}$ & $15.4 *(57 \%)$ & $13.8(57 \%)$ & $16.3(64 \%)$ & $10.6(57 \%)$ & $15.4(57 \%)$ & $15.4(57 \%)$ & $15.4(57 \%)$ \\
\hline $\begin{array}{l}\text { Continental DMS } \\
\text { emission flux }\end{array}$ & $0.3(1 \%)$ & $0.3(1 \%)$ & $0.3(1 \%)$ & $0.3(2 \%)$ & $0.3(1 \%)$ & $0.3(1 \%)$ & $0.3(1 \%)$ \\
\hline $\begin{array}{l}\text { Oxidation by } \\
\mathrm{OH} \text { to } \mathrm{SO}_{2}\end{array}$ & $15.5(57 \%)$ & $13.1(53 \%)$ & $13.8(53 \%)$ & $10.5(57 \%)$ & $9.0(33 \%)$ & $14.1(52 \%)$ & $10.6(39 \%)$ \\
\hline $\begin{array}{l}\text { Oxidation by } \\
\mathrm{NO}_{3} \text { to } \mathrm{SO}_{2}\end{array}$ & $7.7(29 \%)$ & $8.2(34 \%)$ & $8.4(33 \%)$ & $5.4(29 \%)$ & $15.7(58 \%)$ & $7.0(26 \%)$ & $6.2(23 \%)$ \\
\hline $\begin{array}{l}\text { Oxidation by } \\
\text { OH to DMSO }\end{array}$ & $3.9(14 \%)$ & $3.1(13 \%)$ & $3.5(14 \%)$ & $2.6(14 \%)$ & $2.4(9 \%)$ & $3.4(13 \%)$ & $2.5(9 \%)$ \\
\hline $\begin{array}{l}\text { Oxidation by } \\
\mathrm{O}_{3} \text { (gas phase) }\end{array}$ & - & - & - & - & - & $0.9(3 \%)$ & - \\
\hline $\begin{array}{l}\text { Oxidation by } \\
\mathrm{O}_{3} \text { (aqueous phase) }\end{array}$ & - & - & - & - & - & $1.7(6 \%)$ & - \\
\hline Oxidation by $\mathrm{BrO}$ & - & - & - & - & - & - & $7.8(29 \%)$ \\
\hline DMS burden & 0.084 & 0.075 & 0.089 & 0.058 & 0.060 & 0.071 & 0.054 \\
\hline DMS residence time & 1.1 & 1.1 & 1.2 & 1.1 & 0.8 & 0.9 & 0.7 \\
\hline Sulphate burden & 0.748 & 0.733 & 0.731 & 0.682 & 0.717 & 0.742 & 0.715 \\
\hline $\begin{array}{l}\text { Sulphate aerosol } \\
\text { indirect RF }\end{array}$ & -0.99 & -1.07 & -1.12 & -1.15 & -0.97 & -1.00 & -1.04 \\
\hline
\end{tabular}

* The oceanic fluxes of DMS obtained using the earlier version of the climatology (Kettle et al., 1999) are 27.9, 12.8, and 15.1 Tg S yr ${ }^{-1}$ for $^{2}$ the globe, the $\mathrm{NH}$, and the $\mathrm{SH}$, respectively.

during summer is among the lowest of the Southern Ocean according to SeaWiFS observations. In fact DMS rich waters occupy a small portion of the Bellingshausen Sea (Turner et al., 1995). In EXP1, these large concentrations result from the assimilation methodology of Kettle and Andreae which applies in this region large oceanic DMS levels from other biogeochemical provinces. The relatively low levels of atmospheric oxidants also contribute to enhance the concentrations of atmospheric DMS.

There are few long-term measurements of atmospheric DMS concentrations. We compare here the modelled atmospheric DMS and $\mathrm{SO}_{2}$ mixing ratios to measurements made at Amsterdam Island in the Southern Ocean (Fig. 5a and b). The EXP1 predicted concentrations and seasonal variations appear to be in reasonable agreement with measured values. However the very large concentrations during the January month is not reproduced by any of the model experiments. EXP2 and EXP3 do not perform well at Amsterdam Island.
We already know that Kettle and Andreae (2000) and SeaWiFS DMS datasets are much better constrained in the Northern than in the Southern Hemisphere because most of the insitu Chl $a$ and DMS measurements used to generate the climatology (Kettle and Andreae, 2000) or to estimate the DMS to Chl $a$ relationship (Belviso et al., 2002) were performed in northern oceans. In the Indian sector of the Southern Hemisphere, the SeaWiFS DMS dataset is much better constrained by observations in August than in December (Belviso et al., 2002). This is also reflected in Fig. 5a where the agreement between EXP1 and EXP2 (and also EXP3) is better in August than in December. In May, June, July, and September, the marine fields of DMS are poorly constrained by observations. So it is in August when marine data offer the best opportunity to investigate the winter photochemistry of DMS. At Cape Grim EXP1 performs better than EXP2 and EXP3 (Fig. 5c). This does not imply that EXP1 would also perform better at lower or higher latitudes of the Southern Ocean, 

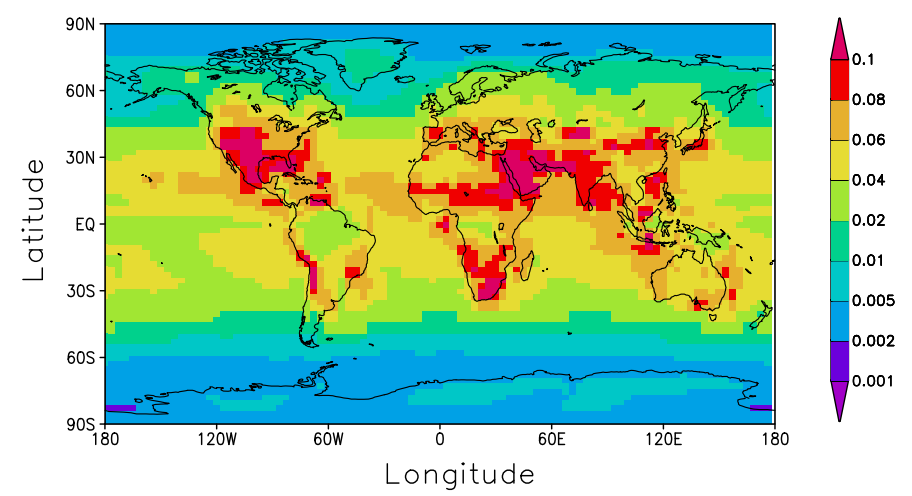

a) IMAGES OH

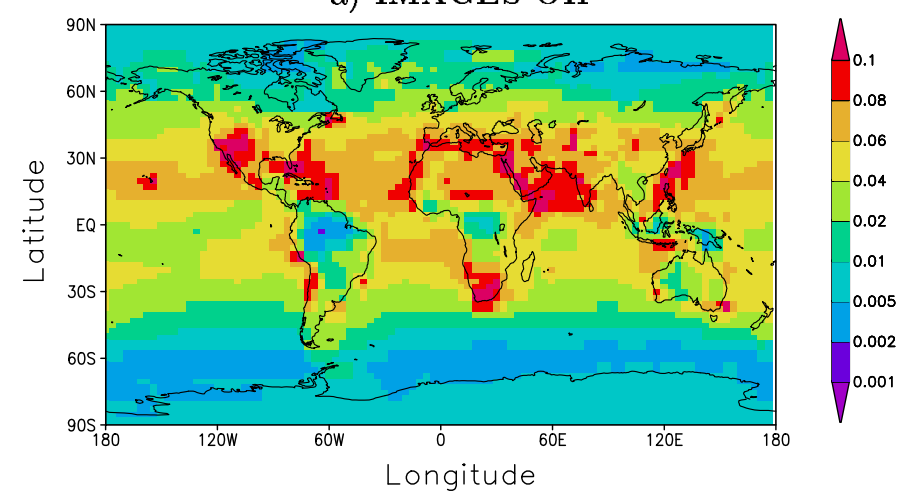

b) MATCH-MPIC OH

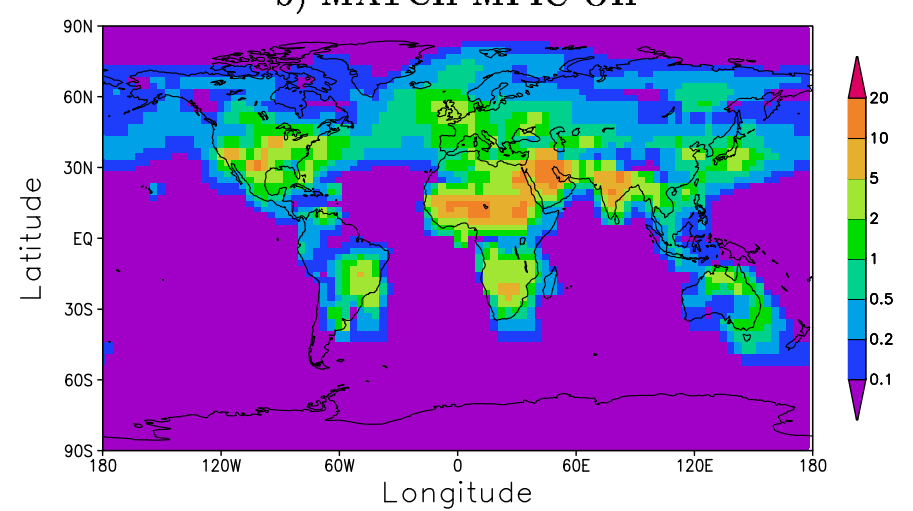

c) IMAGES $\mathrm{NO}_{3}$

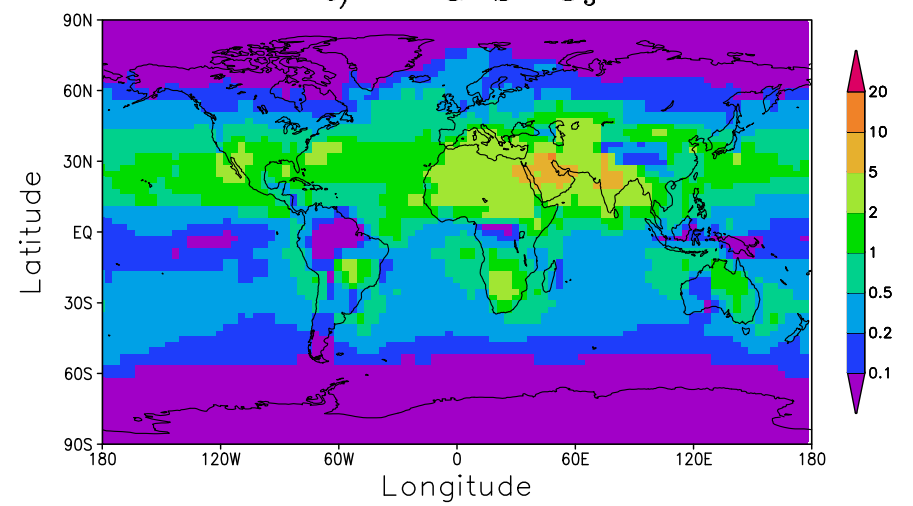

d) MATCH-MPIC $\mathrm{NO}_{3}$

Fig. 7. Annually-averaged $\mathrm{OH}$ and $\mathrm{NO}_{3}$ mixing ratios (pptv) at the surface in IMAGES (a, c) (EXP1) and MATCH-MPIC (b, d) (EXP5). 
where the DMS concentrations are less constrained by actual measurements.

We also compare in Fig. 6 the monthly-mean DMS mixing ratios simulated by the model with the mixing ratios measured during the Albatross cruise in the Atlantic Ocean (Sciare et al., 2000a). At most latitudes the observed values lie within the variability simulated by the model, with a noticeable exception in the $30-40^{\circ} \mathrm{N}$ transect where the observed peak in concentration is not reproduced. This peak is due to the transport of air masses from further south at $20-30^{\circ} \mathrm{N}$ (Sciare et al., 2000a) and these particular meteorological conditions are not simulated here.

From these comparisons we see that it is difficult to establish which DMS climatology performs best. This clearly points to the need for more numerous continuous long-term measurements of atmospheric DMS in the North Atlantic Ocean and elsewhere.

\subsection{Atmospheric DMS budget: $\mathrm{OH}$ versus $\mathrm{NO}_{3}$ oxidation}

Table 2 summarises the global annual atmospheric budget of DMS. The different spatial and temporal distributions of DMS emissions result in a different partitioning of DMS oxidation, with a slightly larger role played by $\mathrm{NO}_{3}$ oxidation in the case of the SeaWiFS and Aumont et al. DMS source (8.24 and $8.42 \mathrm{Tg} \mathrm{S} \mathrm{yr}^{-1}$ in EXP2 and EXP3, respectively) compared to the Kettle and Andreae (2000) case (7.75 $\mathrm{Tg} \mathrm{S} \mathrm{yr}^{-1}$ in EXP1).

There are significant differences in the DMS oxidation if the oxidant fields are prescribed from the MATCH-MPIC model (EXP5) or from the IMAGES model (EXP1). The relative contributions of $\mathrm{DMS}+\mathrm{OH}$ and $\mathrm{DMS}+\mathrm{NO}_{3}$ pathways are opposite. This results from similar distributions of $\mathrm{OH}$ radical but very different distributions of the $\mathrm{NO}_{3}$ radical over the oceans between the two chemical models (Fig. 7). These differences remain unresolved at the moment but may be due to different treatments of NMHCs and/or $\mathrm{NO}_{3}$ heterogeneous sink in the two models. The larger contribution of $\mathrm{NO}_{3}$ to DMS oxidation in EXP5 is accompanied by a significant decrease in the DMS burden and lifetime $(0.060 \mathrm{Tg} \mathrm{S}$ and 0.8 day in EXP5 compared to $0.084 \mathrm{Tg} \mathrm{S}$ and 1.1 day in EXP1). The decrease in DMS concentration in EXP5 compared to EXP1 occurs throughout the troposphere (Fig. 8a) but it is more pronounced in the $0-30^{\circ} \mathrm{N}$ latitude band and above $100 \mathrm{hPa}$.

3.4 Atmospheric DMS budget: importance of new additional oxidation pathways

In EXP6, the gas- and aqueous-phase oxidations of DMS by $\mathrm{O}_{3}$ account for 3.5 (upper limit) and $6.2 \%$ of the total DMS oxidation rate, respectively. The aqueous-phase reaction contributes $15-30 \%$ over the regions north to $60^{\circ} \mathrm{N}$ and in the $50-75^{\circ} \mathrm{S}$ latitude band over the oceans (Fig. 9a). This reaction plays an important role in regions with signifi- cant cloud liquid water content and low concentrations of $\mathrm{OH}$ and $\mathrm{NO}_{3}$ radicals. The gas-phase reaction contributes mostly over Antarctica where no other efficient oxidation pathway is present (Fig. 9b). These additional pathways result in DMS concentrations which are up to $50 \%$ smaller at high latitudes and $10-30 \%$ smaller at low and middle latitudes (Fig. 8b).

In order to assess the possible limitation on the $\mathrm{DMS}+\mathrm{O}_{3}$ aqueous reaction rate from the aqueous diffusion rate of both species, the characteristic diffusion and reaction times were calculated for an average cloud drop diameter of $50 \mu \mathrm{m}$, using the DMS and $\mathrm{O}_{3}$ concentrations obtained between 50 $70^{\circ} \mathrm{N}$ and $50-70^{\circ} \mathrm{S}$, where this reaction predominates. Using diffusivities and Henry's constants at $298 \mathrm{~K}$ (Gershenzon et al., 2001) for DMS and $\mathrm{O}_{3}$, the estimated diffusion rates are about 100 times faster than the reaction rate, indicating no diffusion limitation, as also previously reported for the aqueous reactions of $\mathrm{SO}_{2}$ with $\mathrm{O}_{3}$ and $\mathrm{H}_{2} \mathrm{O}_{2}$ (Venkataraman et al., 2001).

Oxidation by $\mathrm{BrO}$ is found to be an important sink for DMS in EXP7. Globally it contributes $28.8 \%$ to the total DMS oxidation rate, and up to $60 \%$ at high latitudes (Fig. 9c) where the concentrations of other oxidants are low. However it should be remembered that this experiment is highly idealised. $\mathrm{BrO}$ concentrations are highly variable in space and time, and a uniform mixing ratio of $1 \mathrm{pptv}$ in the MBL is probably an overestimate for some regions or seasons. For instance, the diurnal variations of DMS at Amsterdam Island can be explained with the DMS+OH reaction alone (Sciare et al., 2000c). The EXP7 simulation points to the need for atmospheric measurements of $\mathrm{BrO}$ at mixing ratios well below 1 pptv. As pointed out by Ingham et al. (1999) simultaneous measurements of DMS and DMSO can also provide indirect evidence on the importance of BrO. In fact, Nowak et al. (2001) report such measurements and find a DMSO/DMS ratio that is larger than expected if DMSO was only produced from the $\mathrm{DMS}+\mathrm{OH}$ pathway. However, more data especially at night would be clearly valuable.

\subsection{Production of DMSO}

Fig. 10 shows how the DMSO production (as a fraction of the total DMS oxidation) is distributed spatially in EXP1, EXP6, and EXP7 experiments. As expected from the temperature dependences of the DMS+OH reaction rates, a larger fraction of DMS is oxidised in DMSO in the high latitudes (EXP1, Fig.10a). The asymmetry between the two hemispheres is due to the asymmetry in $\mathrm{NO}_{3}$ concentrations (Fig. 7c) which oxidise more DMS in $\mathrm{SO}_{2}$ in the Northern Hemisphere relative to the Southern Hemisphere. Considering the oxidation of DMS by $\mathrm{O}_{3}$ in the gas- and aqueous-phases (EXP6) leads to enhanced production of DMSO. In this experiment, the fraction of DMS oxidised into DMSO can reach 30 to $40 \%$ and 40 to $50 \%$ in the high latitudes of the Northern and Southern Hemispheres, respectively (Fig. 10b). The simplified introduction of $\mathrm{BrO}$ in our model (EXP7) leads to a very 

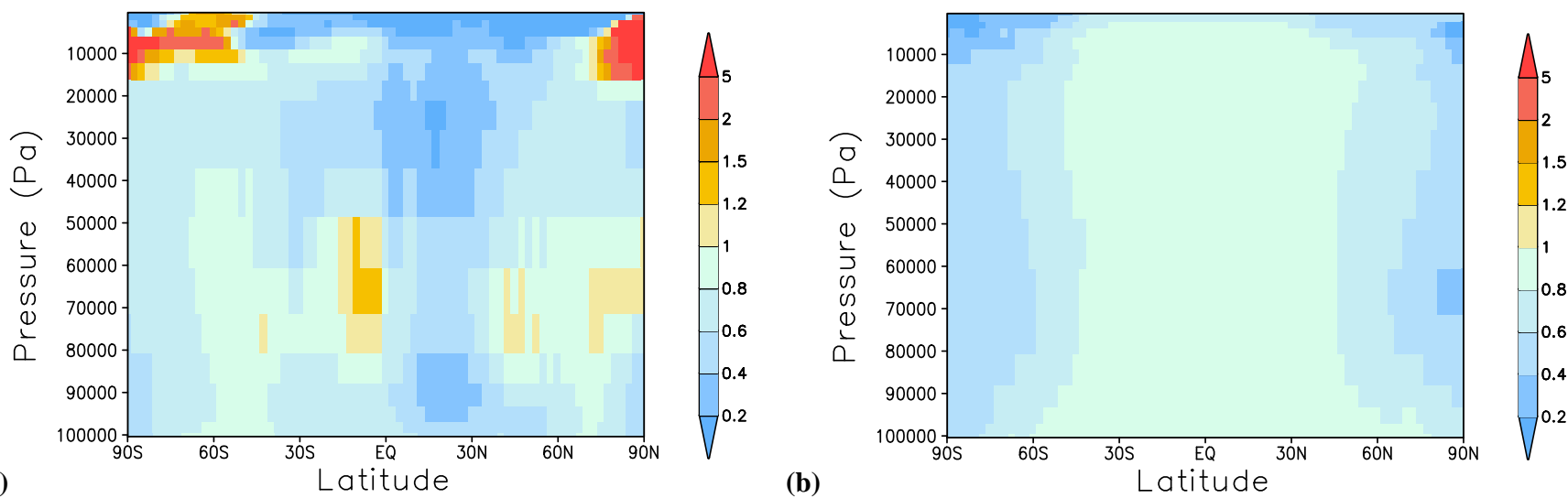

(b)

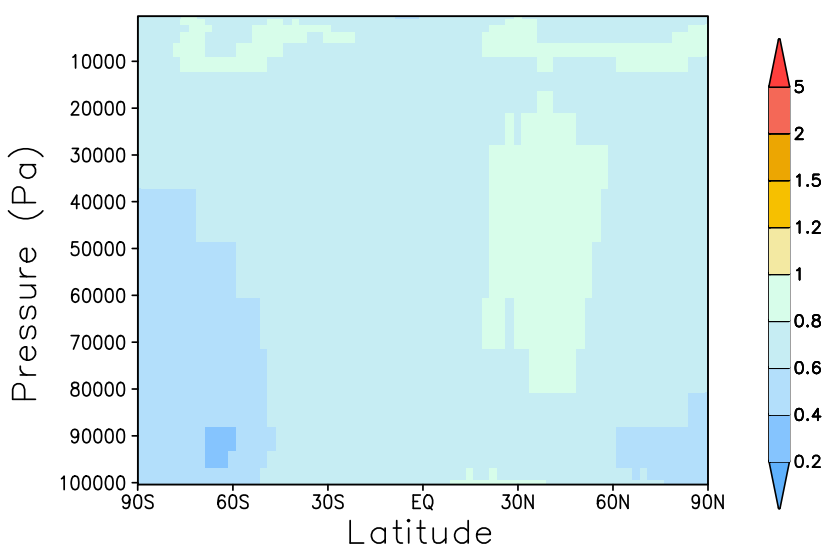

Fig. 8. Ratio of the zonally- and annually-averaged atmospheric DMS mixing ratio from (a) EXP5, (b) EXP6, and (c) EXP7 to that from EXP1.

large production of DMSO which can reach more than $60 \%$ in the high latitudes of the Southern Hemisphere in agreement with the prescribed temperature dependence of the reaction rate (Fig. 10c). While EXP7 may overestimate the production of DMSO, it is nevertheless important to better understand the atmospheric fate of DMSO and establish whether or not it can contribute significantly to the formation of background sulphate aerosols.

\subsection{Indirect radiative forcing of sulphate aerosols}

The spatial distribution of the indirect radiative forcing by anthropogenic sulphate aerosols is very similar in all seven experiments. The indirect radiative forcing is much more sensitive to the assumed relationship between sulphate mass and cloud droplet number concentrations (Boucher and Lohmann, 1995) than the exact distribution of the DMS flux and resulting background sulphate concentration. However, we can estimate the uncertainty in radiative forcing due to uncertainties in the temporal and spatial distributions of the background aerosols (here taken to be sulphate aerosols). The largest difference is between the baseline experiment
EXP1 and EXP4 (see Fig. 11). The increase in DMS flux between the EXP4 and EXP1 experiments results in a 14\% decrease in radiative forcing. This result is again consistent with that of Jones et al. (2001). It stresses the importance to simulate accurately the concentrations of background accumulation-mode aerosols in the pre-industrial and present-day atmospheres, but also in the future atmosphere when climate change may induce changes in DMS emissions (Bopp et al., 2002a, 2002b).

\section{Conclusions}

We tested the sensitivity of the DMS atmospheric budget to the oceanic DMS concentration, the assumed sea-air transfer function, the atmospheric oxidant fields, and additional oxidation paths. The conclusions of the study are the following:

1. Using three different oceanic DMS climatologies results into very similar global DMS fluxes but also into large differences in the spatial and seasonal distribution of the DMS emissions, particularly in the Southern Hemi- 
(a)
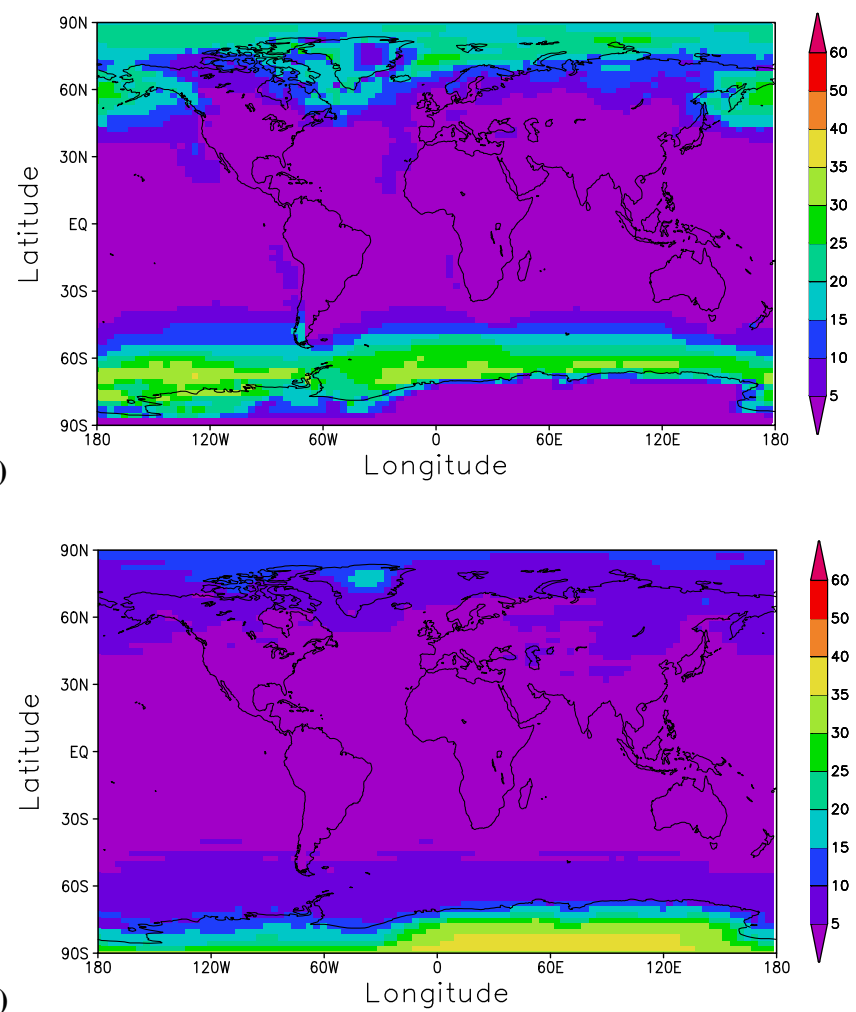

(b)

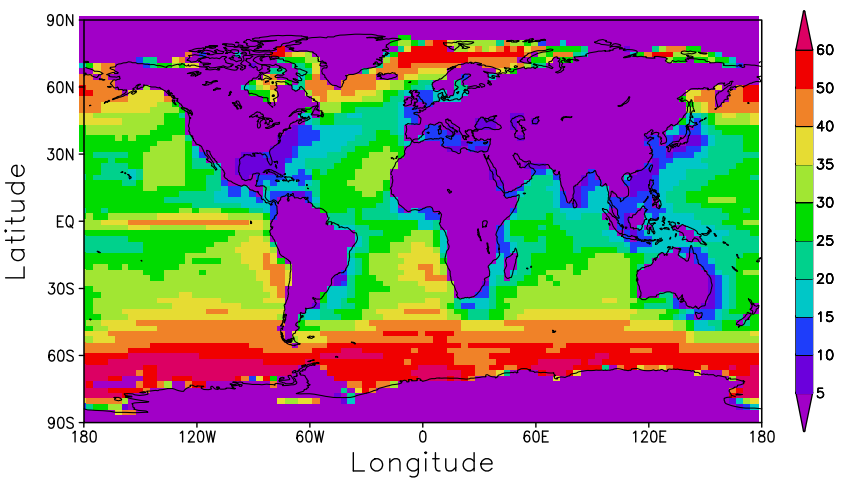

Fig. 9. Relative contribution (\%) of the additional oxidation pathways to the vertically-integrated DMS oxidation rate: (a) $\mathrm{DMS}+\mathrm{O}_{3}$ in aqueous phase (EXP6), (b) $\mathrm{DMS}^{+\mathrm{O}_{3}}$ in gas phase (EXP6), and (c) DMS+BrO (EXP7).

sphere. These differences translate into quite different distributions of atmospheric DMS.

2. Using the more sophisticated parameterisation of DMS sea-air transfer of Nightingale et al. (2000) instead of that of Liss and Merlivat (1986) results in a global DMS flux that is $47 \%$ larger and an indirect radiative forcing by sulphate aerosols that is $14 \%$ smaller.

3. We found significant differences in the relative contributions of $\mathrm{OH}$ and $\mathrm{NO}_{3}$ to DMS oxidation when using oxidant fields from the IMAGES or MATCH-MPIC chemical transport models. This introduces a significant source of uncertainty in the atmospheric DMS cy- cle. Measurements of the concentration of $\mathrm{NO}_{3}$ radical to better constrain the models would be very valuable.

4. Gaseous- and aqueous-phase oxidations of DMS by $\mathrm{O}_{3}$ are found to contribute 3.5 and $6.2 \%$ to the total DMS oxidation, respectively, and up to $30-40 \%$ at high latitudes. These reactions should be incorporated in future modelling studies of the sulphur cycle at high latitudes. Note however that we used an upper limit for the reaction rate of DMS by $\mathrm{O}_{3}$ in gaseous phase, the value of which needs to be refined.

5. Assuming a $\mathrm{BrO}$ mixing ratio of $1 \mathrm{pptv}$ in the marine boundary layer at day, oxidation of DMS by BrO proved 
(a)
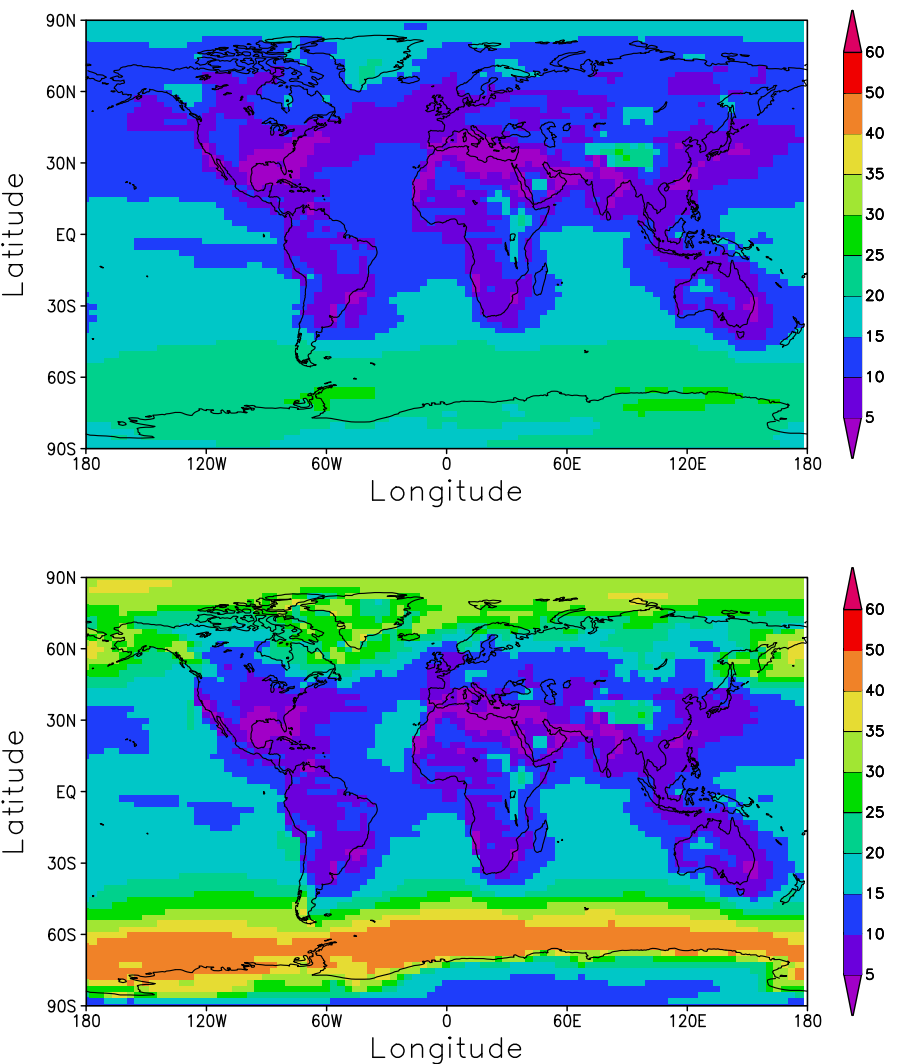

(b)

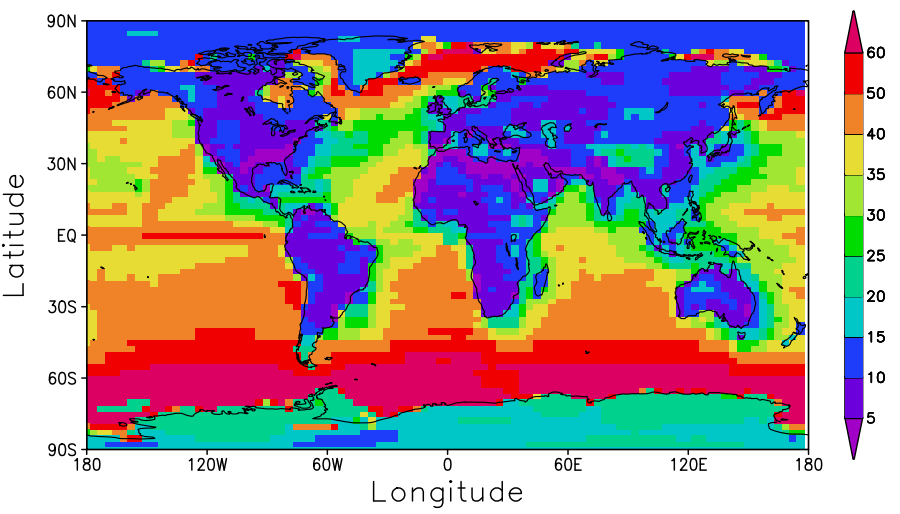

Fig. 10. Fraction (\%) of DMS which is oxidised in DMSO on annual average in (a) EXP1, (b) EXP6, and (c) EXP7.

to be a significant sink for DMS at high latitudes. It is therefore important to measure $\mathrm{BrO}$ in the marine boundary layer down to a detection limit of $\sim 0.1 \mathrm{pptv}$.

6. The oxidation of DMS by $\mathrm{O}_{3}$ in the aqueous phase and by $\mathrm{BrO}$ in the gas phase produces only DMSO. Considering these two reactions results in a very different partitioning of the DMS oxidation between $\mathrm{SO}_{2}$ and DMSO. It is therefore important to better understand the atmospheric fate of DMSO, the importance of heterogeneous sinks, and whether it can contribute to the production of background sulphate aerosols or not (Sciare et al., 2000c).
7. There are very few long-term measurements of atmospheric DMS to evaluate our model. It is not straightforward to select the most realistic simulations from the limited set of atmospheric DMS measurements. This study points to the need for more numerous continuous multi-year measurements of the DMS concentrations not only in seawater and but also in the atmosphere.

Acknowledgements. We thank E. Chapman for providing her seaair transfer routine. Computer time for this study was provided by the "Institut du Développement et des Ressources en Informatique Scientifique" (IDRIS) of the CNRS. This research proposal is supported by the "Programme National des PROcessus 


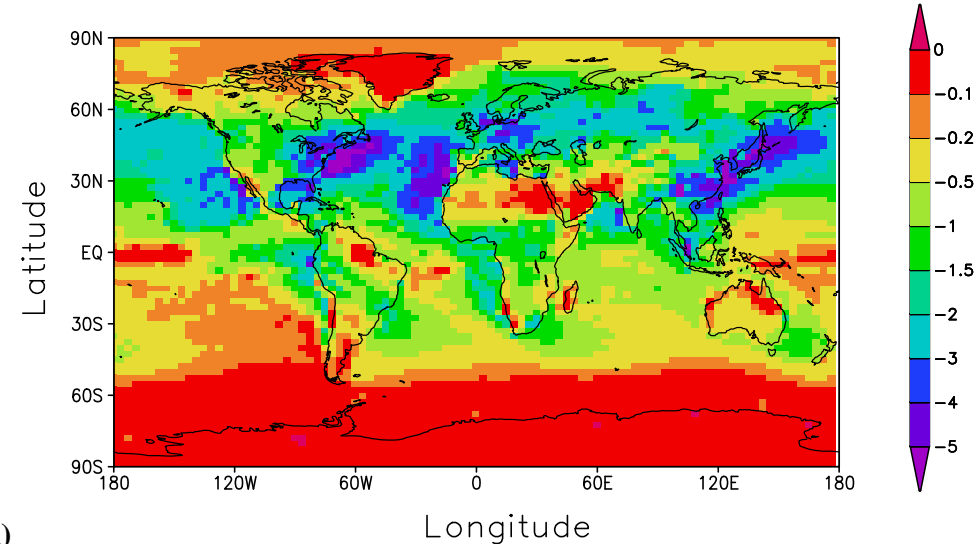

(a)

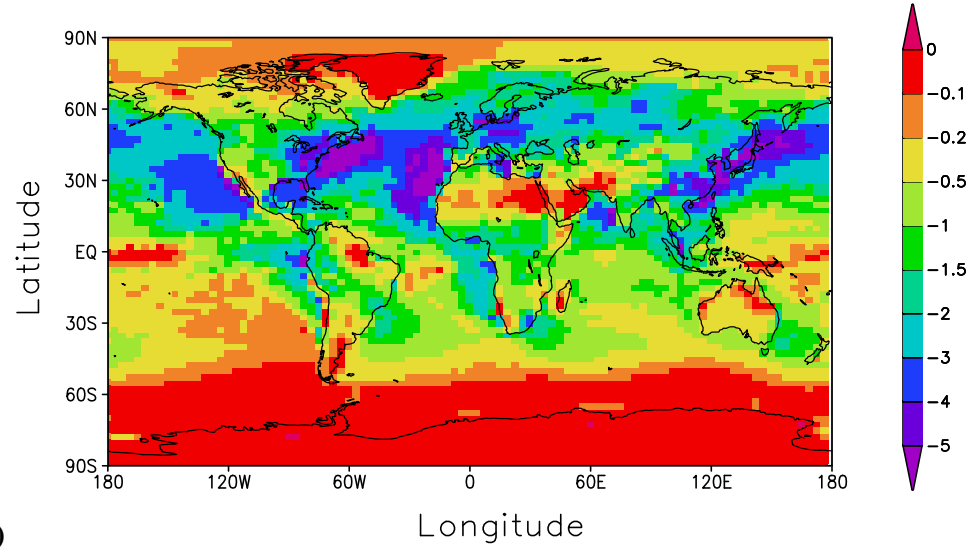

Fig. 11. Spatial distribution of the annually-averaged indirect radiative forcing $\left(\mathrm{Wm}^{-2}\right)$ by sulphate aerosols for (a) EXP1 and (b) EXP4.

biogéochimiques dans l'Océan et Flux" (PROOF) and the "Programme National de Chimie atmosphérique" (PNCA) of the CNRS. M. S. Reddy acknowledges support from the Indo-French IFCPAR programme and the EU-funded PHOENICS project EVK2CT-2001-00098. Olivier Boucher would like to thank the hospitality of P. Crutzen, J. Lelieveld, and the Max Planck Institute for Chemistry in Mainz, where part of this study was performed. The "Institut Polaire Français - Paul-Emile Victor" (IPEV) is acknowledged for its support to long-term measurements at the Amsterdam Island. The Laboratoire d'Optique Atmosphérique is an institute of the "Fédération de Recherche" FR1818 of the CNRS.

\section{References}

Aumont, O., Belviso, S., and Monfray, P.: Dimethylsulfoniopropionate (DMSP) and dimethylsulfide (DMS) sea surface distributions simulated from a global three-dimensional ocean carbon cycle model, J. Geophys. Res., 107, (C4), 3029, 10.1029/1999JC000111, 2002.

Ayers, G. P., Ivey, J. P., and Gillett, R. W.: Coherence between the seasonal cycles of dimethyl sulphide, methanesulphonate, and sulphate in marine air, Nature, 349, 404-406, 1991.

Barth, M. C., Rasch, P. J., Kiehl, J. T., Benkovitz, C. M., and Schwartz, S. E.: Sulfur chemistry in the National Center for Atmospheric Research Community Climate Model: Description, evaluation, features, and sensitivity to aqueous chemistry, J. Geophys. Res., 105, 1387-1415, 2000.

Belviso, S., Moulin, C., Bopp, L., Stefels, J.: Assessment of a global climatology of oceanic dimethylsulfide (DMS) concentrations based on SeaWiFS imagery (1998-2001), Can. J. Fish. Aquat. Sci., submitted, 2002.

Bopp, L., Aumont, O., Belviso, S., and Monfray, P.: Potential impact of climate change on marine dimethylsulfide emissions, Tellus, in press, 2002a.

Bopp, L., Boucher, O., Aumont, O., Belviso, S., Dufresne, J.-L., Monfray, P., and Pham, M.: Will marine dimethylsulfide emissions amplify or alleviate global warming? - A model study, Can. J. Fish. Aquat. Sci., submitted, 2002b.

Boucher, O. and Lohmann, U.: The sulfate-CCN-cloud albedo effect: A sensitivity study with two general circulation models, Tellus, 47B, 281-300, 1995.

Boucher, O. and Pham, M.: History of sulfate aerosol radiative forcings, Geophys. Res. Lett., 29(9), 1308, 10.1029/2001GL014048, 2002.

Boucher, O., Pham, M., and Venkataraman, C.: Simulation of the atmospheric sulfur cycle in the Laboratoire de Météorologie Dynamique General Circulation Model. Model description, model evaluation, and global and European budgets, Note scientifique de l'Institut Pierre Simon Laplace, Paris, France, 2002.

(http://www.ipsl.jussieu.fr/poles/Modelisation/NotesSciences. htm) 
Campolongo, F., Saltelli, A., Jensen, N. R., Wilson, J., and Hjorth, J.: The role of multiphase chemistry in the oxidation of dimethylsulfide (DMS). A latitude dependent analysis, J. Atmos. Chem., 32, 327-356, 1999.

Charlson, R. J., Lovelock, J. E., Andreae, M. O., and Warren, S. G.: Oceanic phytoplankton, atmospheric sulphur, cloud albedo and climate, Nature, 326, 655-661, 1987.

Chin, M., Rood, R. B., Allen, D. J., Andreae, M. O., Thompson, A. M., Lin, S.-J., Atlas, R. M., and Ardizzone, J. V.: Processes controlling dimethylsulfide over the ocean: Case studies using a 3-D model driven by assimilated meteorological fields, J. Geophys. Res., 103, 8341-8354, 1998.

Chin, M., Rood, R. B., Lin, S.-J., Müller, J.-F., and Thompson, A. M.: Atmospheric sulfur cycle simulated in the global model GOCART: model description and global properties, J. Geophys. Res., 105, 24 671-24 688, 2000.

Corbett, J. J., Fischbeck, P. S., and Pandis, S. N.: Global nitrogen and sulfur inventories for ocean-going ships, J. Geophys. Res., 104, 3457-3470, 1999.

Cosme, E., Genthon, C., Martinerie, P., Pham, M., and Boucher, O.: Sulfur cycle in the high southern latitudes in the LMD-ZT general circulation model, J. Geophys. Res., 107 (D23), 4690, 10.1029/2002JD000943, 2002.

Curran, M. A. and Jones, G. B.: Dimethyl sulfide in the Southern Ocean: seasonality and flux, J. Geophys. Res., 105, $20451-$ 20 459, 2000.

DeMore, W. B., Sander, S. P., Golden, D. M., Hampson, R. F., Kurylo, M. J., Howard, C. J., Ravishankara, A. R., Kolb, C. E., and Molina, M. J.: Chemical kinetics and photochemical data for use in stratospheric modeling, Evaluation Number 12, JPL Publication 97-4, Jet Propulsion Lab., Pasadena, CA, 1997.

Dentener, F. J. and Crutzen, P. J.: Reaction of $\mathrm{N}_{2} \mathrm{O}_{5}$ on tropospheric aerosols: Impact on the global distributions of $\mathrm{NO}_{x}, \mathrm{O}_{3}$, and $\mathrm{OH}$, J. Geophys. Res., 98, 7149-7163, 1993.

Gershenzon, M., Davidovits, P., Jayne, J. T., Kolb, C. E., and Worsnop, D. R.: Simultaneous uptake of DMS and ozone on water, J. Physical Chemistry A, 105, 7031-7036, 2001.

Granier, C., Hao, W. M., Brasseur, G., and Müller, J.-F.: Land use practices and biomass burning: Impact on the chemical composition of the atmosphere, in Biomass Burning and Global Change, edited by J. S. Levine, pp. 140-148, MIT Press, Cambridge, Mass., 1996.

Gros, V., Poisson, N., Martin, D., Kanakidou, M., and Bonsang, B.: Observations and modeling of the seasonal variation of surface ozone at Amsterdam Island: 1994-1996, J. Geophys. Res., 103, 28 103-28 109, 1998.

Hausmann, M. and Platt, U.: Spectroscopic measurements of bromine oxide and ozone in the high Arctic during the Polar Sunrise Experiment 1992, J. Geophys. Res., 99, 25 399-25 413, 1994.

Hebestreit, K., Stutz, J., Rosen, D., Matveiv, V., Peleg, M., Luria, M., and Platt, U.: DOAS measurements of tropospheric bromine oxide in mid-latitudes, Science, 283, 55-57, 1999.

Ingham, T., Bauer, D., Sander, R., Crutzen, P. J., and Crowley, J. N.: Kinetics and products of the reactions $\mathrm{BrO}+\mathrm{DMS}$ and $\mathrm{Br}+$ DMS at 298 K, J. Physical Chemistry A, 103, 7199-7209, 1999.

Jones, A., Roberts, D. L., Woodage, M. J., and Johnson, C. E.: Indirect sulphate aerosol forcing in a climate model with an interactive sulphur cycle, J. Geophys. Res., 106, 20 293-20310, 2001.

Kettle, A. J., Andreae, M. O., and Amouroux, D., et al.: A global database of sea surface dimethylsulfide (DMS) measurements and a procedure to predict sea surface DMS as a function of latitude, longitude, and month, Global Biogeochem. Cycles, 13, 399-444, 1999.

Kettle, A. J. and Andreae, M. O.: Flux of dimethylsulfide from the oceans: A comparison of updated data sets and flux models, J. Geophys. Res., 105, 26 793-26 808, 2000.

Koch, D., Jacob, D., Tegen, I., Rind, D., and Chin, M.: Tropospheric sulfur simulation and sulfate direct radiative forcing in the Goddard Institute for Space Studies general circulation model, J. Geophys. Res., 104, 23 799-23 822, 1999.

Lawrence, M. G., Crutzen, P. J., Rasch, P. J., Eaton, B. E., and Mahowald, N. M.: A model for studies of tropospheric photochemistry: Description, global distributions, and evaluation, J. Geophys. Res., 104, 26 245-26 277, 1999.

Lee, Y.-N. and Zhou, X.: Aqueous reaction kinetics of ozone and dimethylsulfide and its atmospheric importance, J. Geophys. Res., 99, 3597-3605, 1994.

Liss, P. S. and Merlivat, L.: Air-sea gas exchange rates: Introduction and synthesis, in: Menard, P. B. and Reidel, D. (Eds.): The Role of Air-Sea Exchange in Geochemical Cycling, Norwell, Mass, 113-127, 1986.

Lohmann, U., Feichter, J., Penner, J., and Leaitch, R.: Indirect effect of sulfate and carbonaceous aerosols: A mechanistic treatment, J. Geophys. Res., 105, 12 193-12 206, 2000.

Martinez, R. I. and Herron, J. T.: Stopped-flow study of the gasphase reaction of ozone with organic sulfides: Dimethyl sulfide, Int. J. Chem. Kinetics, 10, 433-452, 1978.

Müller, J.-F. and Brasseur, G. P.: IMAGES: A three-dimensional chemical transport model of the global troposphere, J. Geophys. Res., 100, 16 445-16 490, 1995

Nakano, Y., Goto, M., Hashimoto, S., Kawasaki, M., and Wallington, T. J.: Cavity ring-down spectroscopic study of the reactions of $\mathrm{Br}$ atoms and $\mathrm{BrO}$ radicals with dimethyl sulfide, J. Physical Chemistry A, 105, 11 045-11 050, 2001.

Nightingale, P. D., Malin, G., Law, C. S., Watson, A. J., Liss, P. S., Liddicoat, M. I., Boutin, J., and Upstill-Goddard, R. C.: In situ evaluation of air-sea exchange parameterizations using novel conservative and volatile tracers, Global Biogeochem. Cycles, 14, 373-387, 2000.

Nowak, J. B., Davis, D. D., Chen, G., Eisele, F. L., Mauldin, R. L., Tanner, D. J., Cantrell, C., Kosciuch, E., Bandy, A., Thornton, D., and Clarke, A.: Airborne observations of DMSO, DMS, and $\mathrm{OH}$ at marine tropical latitudes, Geophys. Res. Lett., 28, 22012204, 2001.

Penner, J. E., Andreae, M., Annegarn, H., Barrie, L., Feichter, J., Hegg, D., Jayaraman, A., Leaitch, R., Murphy, D., Nganga, J., and Pitari, G.: Aerosols, their Direct and Indirect Effects, in Climate Change 2001: The scientific basis, Cambridge University Press, 289-348, 2001.

Pham, M., Müller, J.-F., Brasseur, G., Granier, C., and Mégie, G.: A three-dimensional study of the tropospheric sulfur cycle, J. Geophys. Res., 100, 26 061-26092, 1995.

Pickering, K. E., Wang, Y., Tao, W.-K., Price, C., and Müller, J.F.: Vertical distributions of lightning NOx for use in regional and global chemical transport models, J. Geophys. Res., 103, 31203 $31216,1998$.

Price C., Penner, J., and Prather, M.: $\mathrm{NO}_{x}$ from lightning, 1. Global distribution based on lightning physics, J. Geophys. Res., 102, 5929-5941, 1997. 
Putaud, J.-P., Mihalopoulos, N., Nguyen, B. C., Campin, J. M., and Belviso, S.: Seasonal variations of atmospheric sulfur dioxide and dimethylsulfide concentrations at Amsterdam Island in the Southern Indian Ocean, J. Atmos. Chem., 15, 117-131, 1992.

Sciare, J., Baboukas, E., Kanakidou, M., Krischke, U., Belviso, S., Bardouki, H., and Mihalopoulos, N.: Spatial and temporal variability of atmospheric sulfur-containing gases and particles during the Albatross campaign, J. Geophys. Res., 105, 1443314448, 2000a.

Sciare, J., Mihalopoulos, N., and Dentener, F. J.: Interannual variability of atmospheric dimethylsulfide in the southern Indian Ocean, J. Geophys. Res., 105, 26369-26378, 2000b.

Sciare, J., Kanakidou, M., and Mihalopoulos, N.: Diurnal and seasonal variation of atmospheric dimethylsulfoxide at Amsterdam Island in the southern Indian Ocean, J. Geophys. Res., 105, 17 257-17 265, 2000c.

Sciare, J., Baboukas, E., Mihalopoulos, N.: Short-term variability of atmospheric DMS and its oxidation products at Amsterdam Island during summer time, J. Atmos. Chem., 39, 281-302, 2001.

Shaw, G. E.: Bio-controlled thermostasis involving the sulfur cycle, Clim. Change, 5, 297-303, 1983.

Toumi, R.: BrO as a sink for dimethylsulfide in the marine atmosphere, Geophys. Res. Lett., 21, 117-120, 1994.

Turner, S. M., Nightingale, P. D., Broadgate, W., and Liss, P. S.: The distribution of dimethyl sulfide and dimethylsulphoniopropi- onate in Antarctic waters and sea ice, Deep-Sea Res., 42, 10591080, 1995.

Venkataraman, C., Mehra, A., and Mhaskar, P.: Mechanisms of sulphate aerosol production in clouds: effect of cloud characteristics and season in the Indian region, Tellus, 53B, 260-272, 2001.

von Glasow, R., Sander, R., Bott A., and Crutzen, P. J.: Modeling halogen chemistry in the marine boundary layer. 2. Interactions with sulfur and the cloud-covered MBL, J. Geophys. Res., 107 (D17), 4323, 10.1029/2002JD000943, 2002.

von Kuhlmann, R.: Tropospheric photochemistry of $\mathrm{O}_{3}$, its precursors and the hydroxyl radical: A 3D modeling study considering non-methane hydrocarbons, University of Mainz, Mainz, Germany, PhD Thesis, 2001. (available via http://www.mpch-mainz. mpg.de/ kuhlmann)

von Kuhlmann, R., Lawrence, M. G., Crutzen, P. J., and Rasch, P. J.: A model for studies of tropospheric ozone and non-methane hydrocarbons: model description and ozone results, J. Geophys. Res., 10.1029/2002JD002893, 2003.

Wanninkhof, R.: Relationship between wind speed and gas exchange over the ocean, J. Geophys. Res., 97, 7373-7382, 1992.

Yvon, S. A., Saltzman, E. S., Cooper, D. J., Bates, T. S., and Thompson, A. M.: Atmospheric sulfur cycling in the tropical Pacific marine boundary layer $\left(12^{\circ} \mathrm{S}, 135^{\circ} \mathrm{W}\right)$ : A comparison of field data and model results, 1. Dimethylsulfide, J. Geophys. Res., 101, 6899-6909, 1996. 